\title{
Online Model-based Fault Detection for Grid Connected PV Systems Monitoring
}

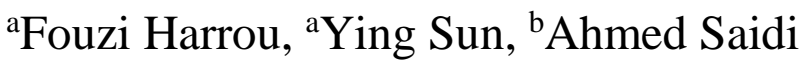

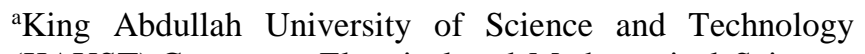
(KAUST),Computer, Electrical and Mathematical Sciences and Engineering (CEMSE) Division, Thuwal 23955-6900, Saudi Arabia, Email: fouzi.harrou@kaust.edu.sa

\author{
${ }^{\mathrm{b}}$ Electrical Engineering Department, Smart grid \& \\ renewable energy (SG\&RE) Laboratory \\ TAHRI Mohammed University, Béchar, Algeria \\ Email: ahmedsaidi@outlook.com
}

\begin{abstract}
This paper presents an efficient fault detection approach to monitor the direct current (DC) side of photovoltaic (PV) systems. The key contribution of this work is combining both single diode model (SDM) flexibility and the cumulative sum (CUSUM) chart efficiency to detect incipient faults. In fact, unknown electrical parameters of SDM are firstly identified using an efficient heuristic algorithm, named Artificial Bee Colony algorithm. Then, based on the identified parameters, a simulation model is built and validated using a co-simulation between Matlab/Simulink and PSIM. Next, the peak power (Pmpp) residuals of the entire PV array are generated based on both real measured and simulated Pmpp values. Residuals are used as the input for the CUSUM scheme to detect potential faults. We validate the effectiveness of this approach using practical data from an actual 20 MWp grid-connected PV system located in the province of Adrar, Algeria.
\end{abstract}

Keywords- Monitoring; single diode model; artificial bee colony; CUSUM; PV systems.

\section{INTRODUCTION}

Photovoltaic (PV) systems are continuously exposed to many potential external interferences or faults that can cause significant loss of the power production. Faults in DC side of PV systems are often difficult to avoid and can result in energy loss, system shutdown or even in serious safety concerns [1]. For example, two PV facilities in the US (a $383 \mathrm{KWp} \mathrm{PV}$ array in Bakersfield, CA and a 1.208 MWp power plant in Mount Holly, NC) burned in 2009 and 2011, respectively [2]. The source for these accidents was a fault on the DC side that was not identified early [2, 3]. Therefore, an efficient real time monitoring and fault detection strategy is very important, not only to reduce time and cost of maintenance, but also to avoid any kind of energy loss, equipment damages and disastrous accidents [4]. Several monitoring strategies have been proposed in the literature. These strategies could be categorized into two groups: model-based methods and history-based methods. In model-based methods, real measured outputs are compared analytically with computed outputs, a fault is flagged a large difference is detected [5]. Model-based fault detection methods include, single-diodebased fault detection approaches [6-8], Kalman filter [9], and Fourier series [10]. In single diode model (SDM) based methods, the unknown electrical parameters of the employed PV module are firstly identified using an efficient strategy [1, 6], following with maximum power point (MPP) prediction approach based on real onsite climate data measurements. Other methods use sophisticated tools, such as time domain reflectometry (TDR) [11] and thermo-reflectance imaging (TR) [12] based methods have been used in several research studies due to their independency to weather conditions. Specifically, TDR has been used to detect both system degradation and PV string disconnection failures. While TR based method has been used to discover hotspot occurrence in PV systems. However, the TDR based method is limited by its technical requirements to turn off the entire PV system, which leads in reducing the system's energetic performances. In addition, this method requires expensive and sophisticated tools since it needs to analyze input and output reflected signals. Of course, the effectiveness of model-based faultdetection approaches relies on the accuracy of the used models.

On other hand, history-based methods analyze a set of available data collected from the PV system under operation in order to derive an empirical model that will be used for fault detection. Methods in this group use both machine learning and computational intelligent procedures [13-17]. Mekki et al. (2016) proposed an approach using an artificial neural network to evaluate the performances of PV plant under the occurrence of partial shading [13]. Tadj et al. (2014) presented a fuzzy logic based approach has to detect the occurrence of short-circuit failures in PV systems [14]. Pavan et al. (2013) developed an efficient strategy that combines both polynomial 
regression and Bayesian neural network to predict the soiling effect in PV system of large scale [15]. Although both modelbased methods and history-based methods give good results in term of monitoring and fault detection, they still have major limitations in practical viewpoint. In fact the efficiency of model-based methods depends deeply on the accuracy of the used model which could not been always guaranteed under practical operation. In other side, the main issue of historybased method is that they require the availability of a relevant database that describes the system performances under healthy and faulty operation cases [1].

To detect incipient faults in PV system, CUSUM chart would be more effective [16]. In this work, we propose a practical and simple scheme to monitor the DC side of PV system, which merges the flexibility of single-diode model and the sensitivity of the CUSUM control charts to detect insidious changes [16]. Specifically, the residuals, which are the differences between the measured and predicted MPP for the power, obtained from the simulated model are used as the input data of the CUSUM chart to reveal abnormalities. We validate our fault detection strategy using measurements from actual operating $20 \mathrm{MWp}$ grid connected PV system located at the province of Adrar, Algeria.

The remaining of this paper is summarized in the following manner: Section II is allocated to PV model modeling under single diode model presentation; Section III describes briefly CUSUM monitoring chart. In Section IV, the proposed strategy of monitoring and fault detection is described in details. Model validation and faults detection results are summarized in Section V. Finally, Section VI is reserved to the drawn conclusions.

\section{SINGLE-DIODE MODEL}

The single diode model (SDM) is the most commonly utilized model that mimics accurately solar cells and PV modules behaviors in energy generation [17]. In this model, solar cells/PV modules are modeled based on a parallel connection of a light generated current source and a diode, additionally with series and shunt resistances which are accounting to model the resistive losses. The electrical circuit that describes SDM is depicted in Figure 1, while its mathematical description that determines solar cell /PV modules output generated currents and voltages is denoted by Equation (1).

$$
\mathrm{I}=\mathrm{I}_{\mathrm{ph}}-\mathrm{I}_{0}\left(\exp \left(\frac{\mathrm{q}\left(\mathrm{V}+\mathrm{R}_{\mathrm{s}} \mathrm{I}\right)}{\mathrm{nK} \mathrm{K}_{\mathrm{B}} \mathrm{T}}\right)-1\right)-\frac{\mathrm{V}+\mathrm{R}_{\mathrm{s}} \mathrm{I}}{\mathrm{R}_{\mathrm{sh}}}
$$

where: $K_{b}$ is Boltzmann constant $\left(K_{b}=1.3806503 \times 10^{-23} \mathrm{j} / \mathrm{k}\right), \mathrm{n}$ is the diode ideality factor, $I_{0}$ denotes the dark saturation current and $\mathrm{q}$ is the electronic charge $\left(\mathrm{q}=1.60217646 \times 10^{-19}\right.$ C). It can be noticeably stated from Equation 1 that the efficiency of this model to accurately mimic solar cells/PV modules behaviors depends intensely on the values of its five electrical parameters: $\mathrm{I}_{\mathrm{ph}}, \mathrm{I}_{0}, \mathrm{n}, \mathrm{R}_{\mathrm{s}}$ and $\mathrm{R}_{\mathrm{sh}}$.

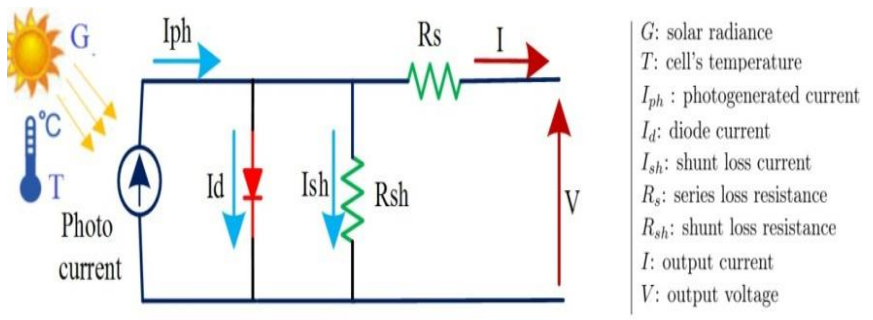

Figure 1. Single Diode Model representation of solar cells/PV modules.

\section{CUSUM MONITORING SCHEME}

Cumulative sum (CUSUM) chart is an efficient statistical method commonly applied in process monitoring and anomalies detection [16, 18, 19]. This scheme sums both past and currents samples in order to make the decision. This chart describes its statistic $\left(\mathrm{S}_{\mathrm{t}}\right)$ by Equation 2 [16].

$$
\mathrm{s}_{\mathrm{t}}=\sum_{\mathrm{j}=1}^{\mathrm{n}}\left(\mathrm{x}_{\mathrm{j}}-\mu_{0}\right)
$$

Where: $S_{t}$ denotes the cumulative sum of the entire samples, comprising the latest samples. $\mu_{0}$ is the targeted mean of the process. In addition, the statistics of this chart can be computed recursively using Equation 3 [16]:

$$
\mathrm{s}_{\mathrm{t}}=\left(\mathrm{x}_{\mathrm{t}}-\mu_{0}\right)+\mathrm{s}_{\mathrm{t}-1}
$$

While the one sided version of CUSUM statistics can be computed using Equation 4:

$$
\mathrm{s}_{\mathrm{t}}=\sum_{\mathrm{j}=1}^{\mathrm{t}}\left[\overline{\mathrm{x}}_{\mathrm{j}}-\left(\mu_{0}+\mathrm{k}\right)\right]
$$

where $\mathrm{k}$ is a reference parameter commonly used to detect insipient changes in the process mean. At the $\mathrm{t}$-th time point, if the CUSUM statistic is beyond the decision threshold, i.e.,

$$
\mathrm{St} \leq \mathrm{H},
$$

Value of $4 \sigma$ or $5 \sigma$ is always suggested by Montgomery in [16] for the parameter $\mathrm{H}$.

\section{THE PROPOSED FAULT DETECTION APPROACH}

This method consists fundamentally on three mains steps: (i) single diode model parameters identification, (ii) the entire PV array simulation model built and experimental validation, and finally (iii) The applying of CUSUM chart on the peak power (Pmpp) residuals, as follows:

\section{1) Step 1: single diode model parameters identification.}

During this stage, the five unknown electrical parameters that define the single diode model parameters are accurately identified using an efficient heuristic algorithm and a set of outdoor (I-V) curve measurements. In fact, SDM parameters 
identification step can be defined as an optimization problem in which the the cost criteria to be minimized is the Root Mean Square Error (RMSE) between real measured (I-V) curve and the estimated one based on the heuristic algorithm as follow:

$$
\operatorname{RMSE}=\sqrt{\frac{\mathrm{I}}{\mathrm{L}} \sum_{\mathrm{i}=1}^{\mathrm{L}}\left[\mathrm{f}_{\mathrm{i}}\left(\mathrm{I}_{\text {meas }}, \mathrm{V}_{\text {meas }}, \theta\right)\right]^{2}}
$$

where

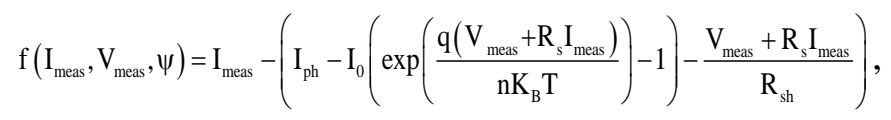

$\psi$ is a vector contains the five unknown electrical parameters (Iph, I0, n, Rs and Rsh), L is the number of the used experimental (I-V) curve data during the parameters extraction process. In this work, Artificial Bee Colony (ABC) algorithm [20-23] has been used to identify accurately the single diode model five unknown parameters.

\section{2) Step 2: PV Array modeling and experimental validation.}

The aim of this stage is to build a simulation model that mimics accurately the real PV array behavior under both healthy and faulty operations. Toward this end, a co-simulation between Matlab/Simulink and PSIM is established in order to simulate the entire PV array using the SDM identified parameters obtained from step 1. Once the model of simulation is built, its accuracy to mimic correctly the physical behavior should be tested by introducing a set of real climate data measurement to the model of simulation, and compare the simulated peak of power Pmpp_sim with the real measured one Pmpp_meas.

\section{3) Step 3: Application of CUSUM monitoring Chart.}

During this phase, the PV array under study is simulated using real climate data measurements of temperature $(T)$ and irradiances $(\mathrm{G})$ for both healthy and faulty operating cases. The aim of this simulation is to extract the peak power $\left(\mathrm{P}_{\mathrm{mpp}}\right)$ values for each operating cases and under several meteorological conditions. Then, based on these $\mathrm{P}_{\mathrm{mpp}}$ values, the residuals $\tilde{P}_{t}=\left[\tilde{P}_{1}, \ldots, \tilde{P}_{t}, \ldots, \tilde{P}_{n}\right]$ which are defined as the difference between real measured and simulated peak power are computed as follow:

$$
\tilde{P}_{t}=P_{t}-\hat{P}_{t} \quad t \in[1, n]
$$

where $P_{t}$ and $\hat{P}_{t}$ denote respectively real measured and estimated power at MPP (peak power). Then, based on these residuals the CUSUM monitoring statistics are computed using Equation 8. Finally, the system will be considered under faulty operation if the CUSUM monitoring statistics $\left(\mathrm{S}_{\mathrm{t}}\right)$ exceed the healthy system allowed decision interval $\mathrm{H}$. otherwise, the system will be considered as under healthy operation.

$$
\mathrm{S}_{\mathrm{t}}=\sum_{\mathrm{j}=1}^{\mathrm{t}}\left[\tilde{\mathrm{P}}_{\mathrm{t}}-\left(\mu_{0}+\mathrm{k}\right)\right]
$$

\section{RESULTS}

The efficiency of this method has been evaluated and tested in this section using real experimental measyrements collected from an actual $20 \mathrm{MWp}$ grid connected PV system located at the province of Adrar. This system is composed of 44 YINGLI (YL245P-29b) PV modules connected as two parallel PV strings of $22 \mathrm{PV}$ modules in series each. Results of SDM parameters identification that concern YINGLI PV module are summarized in Table 1.

TABLE. 1. THE ESTIMATED SDM IDENTIFIED PARAMETERS OF ADRAR PV MODULE.

\begin{tabular}{|l|c|c|c|c|c|c|}
\hline Parameters & $\mathrm{I}_{\mathrm{ph}}[\mathrm{A}]$ & $\mathrm{I}_{0}[\mathrm{~A}]$ & $\mathrm{n}$ & $\mathrm{Rs}[\Omega]$ & $\begin{array}{c}\text { Rsh } \\
{[\Omega]}\end{array}$ & RMSE \\
\hline $\begin{array}{l}\text { Identified } \\
\text { values }\end{array}$ & 8.63 & $1.19 \mathrm{e}-07$ & 1.23 & 0.0075 & 1000 & 0.044 \\
\hline
\end{tabular}

It can be seen clearly from the smaller value of RMSE metric the great efficiency of $\mathrm{ABC}$ algorithm to identify with high accuracy the optimal SDM parameters. Moreover, once these parameters are identified, their corresponding values are then used to build the PV array simulation model based on a cosimulation between Matlab/Simulink and PSIM. This model of simulation has been then experimentally validated by introducing five real climate day profiles of temperature (T) and irradiances $(\mathrm{G})$ into the model, and then compare their corresponding peak power measurement (Pmpp_meas) with the simulated one (Pmpp_sim). Results of the experimental model validation for the five days are depicted in Figure 2. In addition, simulation model validation results have been also evaluated based on computing both RMSE and $\mathrm{r}^{2}$ performance evaluation metrics as follow:

$$
\begin{gathered}
\text { RMSE }=\sqrt{\frac{\sum_{\mathrm{t}=1}^{\mathrm{m}}(\mathrm{P}-\hat{\mathrm{P}})^{2}}{\mathrm{~m}}} \\
\mathrm{r}^{2}=1-\frac{\sum_{\mathrm{t}=1}^{\mathrm{m}}(\mathrm{P}-\hat{\mathrm{P}})^{2}}{\sum_{\mathrm{t}=1}^{\mathrm{m}}(\mathrm{P}-\operatorname{mean}(\mathrm{P}))^{2}}
\end{gathered}
$$

where $\mathrm{P}$ and $\hat{\mathrm{P}}$ are real measured and simulated peak power respectively and $\mathrm{m}$ is the samples number. Scatter plot of real measured and simulated peak power is depicted in Figure 3. 


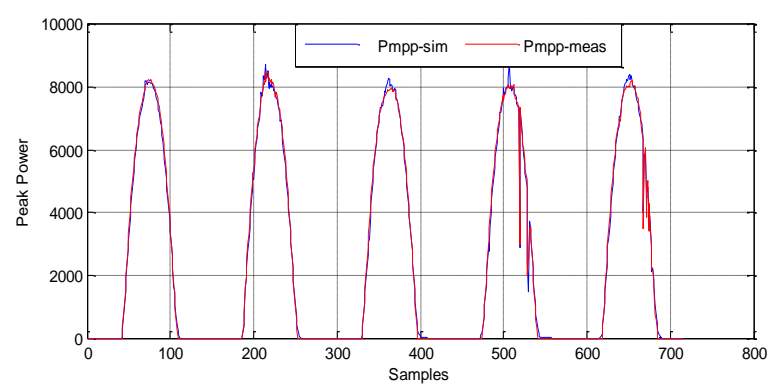

Figure 2. Model validation results of Adrar PV module.

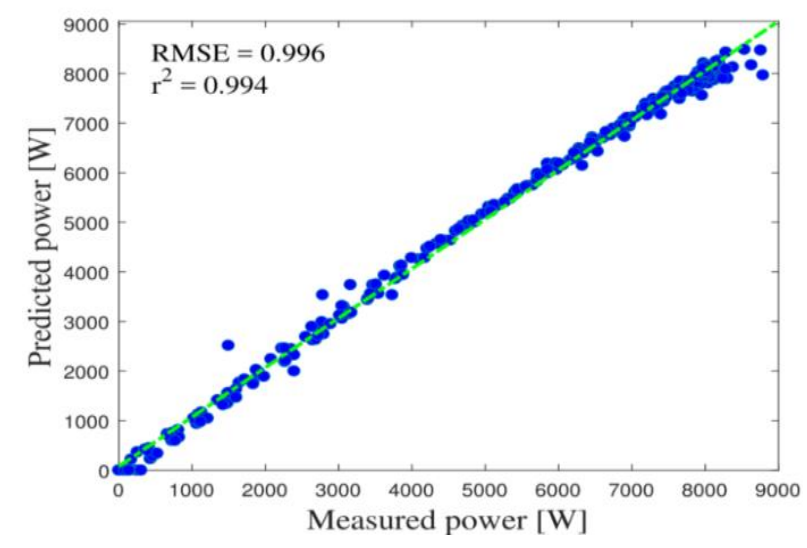

Figure 3. Scatter plot of the measured and predicted peak power.

Once the PV model is validated, the last step consists in testing the efficiency of CUSUM based method to monitor PV system performances. Toward this end, three faulty cases have been tested under Adrar PV system: (1) first string completely disconnected operating case, (2) the presence of eight shortcircuited PV modules in the array operating case and (3) the presence of fourteen short-circuited PV modules in the PV array. Monitoring results of CUSUM chart are shown for the three cases in Figures 4 and 5. The shaded areas in these figures represent the zone for which faults were introduced. CUSUM chart monitoring results show clearly the ability of this method to detect the three faults. In fact, when the system is under normal operation (non-shaded area) CUSUM statistics are below the decision threshold. Then, once a fault is occurred, the values of this statistics exceed the decision threshold. Thus the high efficiency of this method to monitor system performances and detect DC side faults occurrences.

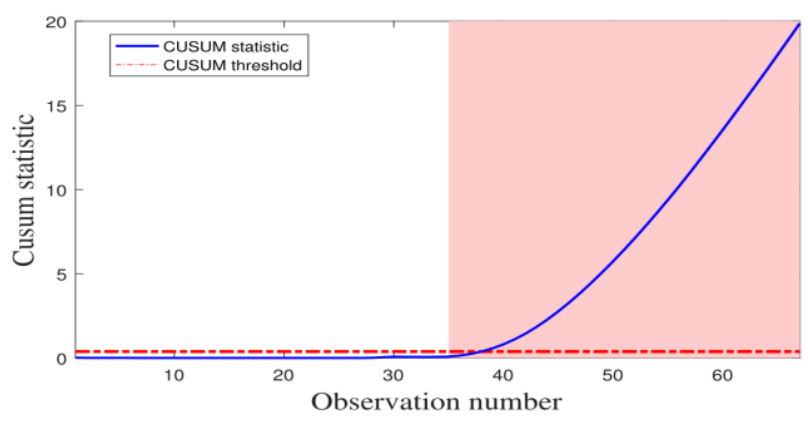

Figure 4. Monitoring results of CUSUM chart for DC power in the presence of an open-circuit fault.

(a)

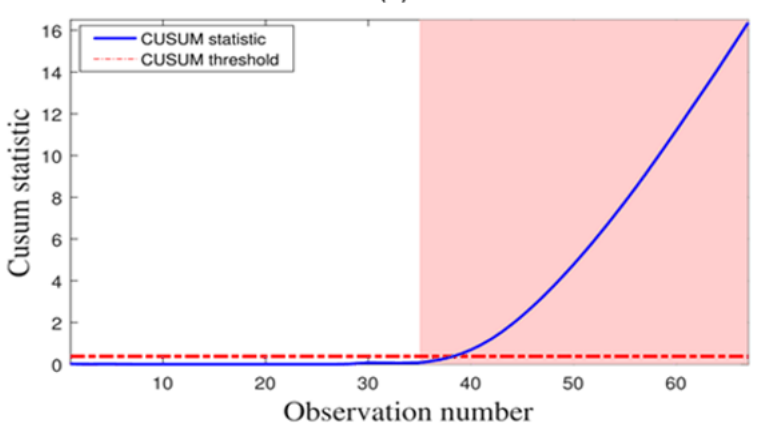

(b)

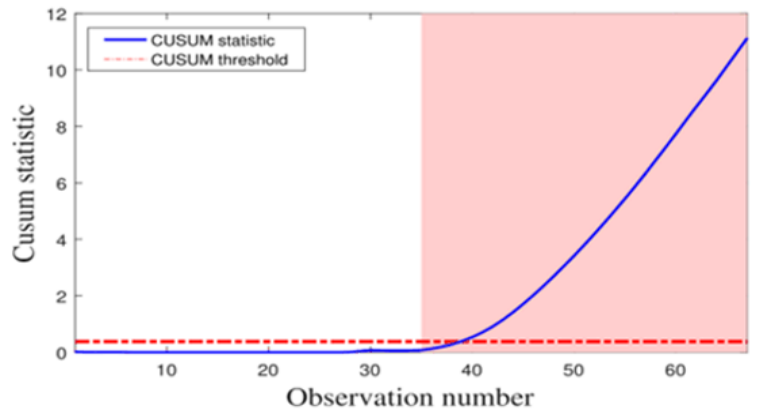

Figure 5. Monitoring results of CUSUM chart for DC power in the presence of (a) eight short-circuited modules and (b) fourteen short-circuited modules in the PV array.

\section{CONCLUSION}

In this paper, a novel fault detection strategy for PV systems monitoring is developed. This strategy allows faults detection and monitoring using an efficient statistical procedure, named CUSUM monitoring chart. The main advantage of this strategy is that it combines both single diode model flexibility and CUSUM scheme efficiency to detect incipient changes. Three main steps are necessary to summarize the proposed method are: (i) identify the SDM parameters, (ii) simulate the entire PV array and validate it experimentally, and finally (iii) apply CUSUM chart to the peak power residuals that are derived from both real measured and simulated DC power. The efficiency of this method has been evaluated and tested experimentally on an actual $20 \mathrm{MWp}$ grid-connected PV system located in the province of Adrar. 
Results show clearly the high efficiency of our method in detecting DC side faults.

\section{ACKNOWLEDGEMENT}

The research reported in this publication was supported by funding from King Abdullah University of Science and Technology (KAUST) Office of Sponsored Research (OSR) under Award No: OSR-2015-CRG4-2582.

\section{REFERENCES}

[1]. Garoudja, E., Harrou, F., Sun, Y., Kara, K., Chouder, A., Silvestre, S., 2017. Statistical fault detection in photovoltaic systems. Solar Energy $150,485-499$.

[2]. Brooks, B., 2011. The bakersfield fire-A lesson in ground-fault protection. SolarPro Mag, 62-70.

[3]. Alam, M., Khan, F., Johnson, J., Flicker, J., 2015. A comprehensive review of catastrophic faults in PV arrays: Types detection, and mitigation techniques. IEEE Journal of Photovoltaics 5 (3), 982-997.

[4]. Hariharan, R., Chakkarapani, M., Ilango, G. S., \& Nagamani, C., 2016. A method to detect photovoltaic array faults and partial shading in PV systems. IEEE Journal of Photovoltaics, 6(5), 1278-1285.

[5]. Harrou, F., Fillatre, L., Nikiforov, I., 2014. Anomaly detection/detectability for a linear model with a bounded nuisance parameter. Annual Reviews in Control 38 (1), 32-44.

[6]. Garoudja, E., Kara, K., Chouder, A., \& Silvestre, S., 2015, May, Parameters extraction of photovoltaic module for long-term prediction using artifical bee colony optimization. In Control, Engineering \& Information Technology (CEIT), 2015 3rd International Conference on (pp. 1-6). IEEE.

[7]. Vergura, S., Acciani, G., Amoruso, V., Patrono, G., Vacca, F., 2009. Descriptive and inferential statistics for supervising and monitoring the operation of PV plants. IEEE Transactions on Industrial Electronics 56 (11), 4456-4464.

[8]. Chao, K., Ho, S., Wang, M., 2008. Modeling and fault diagnosis of a photovoltaic system. Electric Power Systems Research 78 (1), 97-105.

[9]. Kang, B., Kim, S., Bae, S., Park, J., 2012. Diagnosis of output power lowering in a PV array by using the kalman-filter algorithm. IEEE Transactions on Energy Conversion 27 (4), 885-894.

[10]. Johnson, J., Kuszmaul, S., Bower, W., Schoenwald, D., 2011. Using PV module and line frequency response data to create robust arc fault detectors. In: Proceedings of the 26th European Photovoltaic Solar Energy Conference and Exhibition. pp. 05-09.
[11]. Schirone, L., Califano, F., Pastena, M., 1994. Fault detection in a photovoltaic plant by time domain reflectometry. Progress in Photovoltaics: Research and Applications 2 (1), 35-44.

[12]. Hu, Y., Cao, W., Wu, J., Ji, B., Holliday, D., 2014. Thermography-based virtual MPPT scheme for improving PV energy efficiency under partial shading conditions. IEEE transactions on power electronics 29 (11), 5667-5672.

[13]. Mekki, H., Mellit, A., H. Salhi, H., 2016. Artificial neural networkbased modelling and fault detection of partial shaded photovoltaic modules. Simulation Modelling Practice and Theory 67, 1-13.

[14]. Tadj, M., Benmouiza, K., Cheknane, A., Silvestre, S., 2014. Improving the performance of PV systems by faults detection using GISTEL approach. Energy conversion and management 80, 298-304.

[15]. Pavan, A., Mellit, A., Pieri, D., Kalogirou, S., 2013. A comparison between BNN and regression polynomial methods for the evaluation of the effect of soiling in large scale photovoltaic plants. Applied energy $108,392-401$

[16]. Montgomery, D., 2007. Introduction to statistical quality control. John Wiley \& Sons.

[17]. Zeroual A, Harrou F, Sun Y, Messai N, 2017.Monitoring road traffic congestion using a macroscopic traffic model and a statistical monitoring scheme. Sustainable Cities and Society. 35 (November 2017), 494-510.

[18]. Kadri, F., Harrou, F., Chaabane, S., Sun, Y. and Tahon, C., 2016. Seasonal ARMA-based SPC charts for anomaly detection: Application to emergency department systems. Neurocomputing, 173, pp.2102-2114.

[19]. Duffie, J., Beckman, W., 2013. Solar engineering of thermal processes. Vol. 3. Wiley New York.

[20]. Garoudja, E., Kara, K., Chouder, A., Silvestre, S., \& Kichou, S. (2016, November). Efficient fault detection and diagnosis procedure for photovoltaic systems. In Modelling, Identification and Control (ICMIC), 2016 8th International Conference on (pp. 851-856). IEEE.

[21]. Garoudja, E., Harrou, F., Sun, Y., Kara, K., Chouder, A., Silvestre, S., A statistical-based approach for fault detection and diagnosis in a photovoltaic system, 2017 6th International Conference on Systems and Control (ICSC), Batna, Algeria, 2017, pp. 75-80.

[22]. Karaboga, D. (2005). An idea based on honey bee swarm for numerical optimization (Vol. 200). Technical report-tr06, Erciyes university, engineering faculty, computer engineering department.

[23]. Karaboga, D., \& Basturk, B. (2008). On the performance of artificial bee colony (ABC) algorithm. Applied soft computing, 8(1), 687-697. 